\title{
From days to decades: short- and long-term variation in environmental conditions affect offspring diet composition of a marine top predator
}

\author{
Richard J. Howells ${ }^{1,2, *}$, Sarah J. Burthe ${ }^{1}$, Jon A. Green ${ }^{2}$, Michael P. Harris ${ }^{1}$, \\ Mark A. Newell ${ }^{1}$, Adam Butler ${ }^{3}$, David G. Johns ${ }^{4}$, Edward J. Carnell ${ }^{1}$, \\ Sarah Wanless ${ }^{1}$, Francis Daunt ${ }^{1}$ \\ ${ }^{1}$ Centre for Ecology \& Hydrology Edinburgh, Bush Estate, Penicuik, Midlothian EH26 0QB, UK \\ ${ }^{2}$ School of Environmental Sciences, University of Liverpool, Liverpool L69 3GP, UK \\ ${ }^{3}$ Biomathematics \& Statistics Scotland, JCMB, The King's Buildings, Edinburgh EH9 3FD, UK \\ ${ }^{4}$ The Sir Alister Hardy Foundation for Ocean Science, The Laboratory, Citadel Hill, Plymouth PL1 2PB, UK
}

\begin{abstract}
Long-term changes in climate are affecting the abundance, distribution and phenology of species across all trophic levels. Short-term climate variability is also having a profound impact on species and trophic interactions. Crucially, species will experience long- and short-term variation simultaneously, and both are predicted to change, yet studies tend to focus on only one of these temporal scales. Apex predators are sensitive to long-term climate-driven changes in prey populations and short-term effects of weather on prey availability, both of which could result in changes of diet. We investigated temporal trends and effects of long- and short-term environmental variability on chick diet composition in a North Sea population of European shags Phalacrocorax aristotelis between 1985 and 2014. The proportion of their principal prey, lesser sandeel Ammodytes marinus, declined from 0.99 (1985) to 0.51 (2014), and estimated sandeel size declined from 104.5 to $92.0 \mathrm{~mm}$. Concurrently, diet diversification increased from 1.32 (1985) to 11.05 (2014) prey types $\mathrm{yr}^{-1}$, including members of the families Pholidae, Callionymidae and Gadidae. The relative proportion of adult to juvenile sandeel was greater following low sea surface temperatures (SSTs) in the previous year. In contrast, the proportion of Pholidae and prey richness were higher following high SST in the previous year. Within a season, the proportion of sandeel in the diet was lower on days with higher wind speeds. Crucially, our results showed that diet diversification was linked to trends in SST. Thus, predicted changes in climate means and variability may have important implications for diet composition of European shags in the future, with potential consequences for population dynamics.
\end{abstract}

KEY WORDS: Bottom-up control · Climate variability · Weather · Wind · Phalacrocorax aristotelis · Seabird $\cdot$ Sandeel

\section{INTRODUCTION}

The marine environment is changing rapidly, with profound ecological impacts observed across the globe (Poloczanska et al. 2013). Much research has focused on the effects of mean temperature on the distribution, demography and phenology of marine

${ }^{*}$ Corresponding author: ricwel14@ceh.ac.uk animal populations, operating at annual and decadal temporal scales (Edwards \& Richardson 2004, Durant et al. 2007, Sydeman et al. 2015). There is also increasing evidence that shorter scale variability in climate linked to weather conditions can have dramatic fitness consequences (Boyce et al. 2006). However, few studies have considered the effects of climate at

(C) The authors 2017. Open Access under Creative Commons by Attribution Licence. Use, distribution and reproduction are unrestricted. Authors and original publication must be credited. 
multiple temporal scales on wild animal populations (Campbell et al. 2012). Most climate models predict both an increase in mean temperature and the frequency and severity of extreme weather events in many regions (IPCC 2014). Thus, to gain an understanding of how climate change may affect marine animal populations in the future, it is important to quantify the effects of long- and short-term changes in environmental conditions simultaneously.

One of the principal mechanisms whereby climate can affect marine animal populations is through changes in the availability of resources, such as food. Long-term changes in resource availability may occur via alterations in primary production, which propagate through food webs via bottom-up mechanisms (Hays et al. 2005, Perry et al. 2005, Frederiksen et al. 2006). In seasonal environments, climate change may also lead to a spatial or temporal mismatch between resource demand and supply (Fretwell 1972, Durant et al. 2005, Grémillet et al. 2008). Climate variability may also affect resource availability at shorter time scales, by directly altering abundance and distribution, or by affecting consumers' ability to forage (White 2008). In many marine ecosystems, seabirds and other top predators often rely on a small number of prey species (Cury et al. 2000). Top predators may respond to changes in the availability of these main prey within and between seasons by diversifying their diet, in line with optimal foraging theory (Stephens \& Krebs 1986). Such shifts may have important consequences for reproduction and survival, dependent on the relative availability and profitability of different prey.

A number of studies have demonstrated that longterm changes in the distribution, abundance and size of prey have led to changes in seabird diet (Miller \& Sydeman 2004, Gaston \& Elliott 2014, Green et al. 2015). There is also evidence that seabird diet composition is altered by short-term weather conditions such as wind speed (Finney et al. 1999, Stienen et al. 2000, Elliott et al. 2014), mediated by effects on flight performance and prey behaviour and catchability (Sagar \& Sagar 1989, Weimerskirch et al. 2000, Lewis et al. 2015, Kogure et al. 2016). At intermediate temporal scales, diet composition may display seasonal patterns if alternative prey show different scheduling of key life-history events and associated availability (Lewis et al. 2001a, Davoren \& Montevecchi 2003). Such multi-scale temporal effects are important since diet composition is a key determinant of seabird demographic rates (Monaghan et al. 1989, Reid \& Croxall 2001). The sensitivity of seabirds to these effects is particularly pronounced during the breeding season when individuals are faced with high energetic demands, the constraint of foraging close to the colony and potentially high intra-specific competition for food linked to population density (Orians \& Pearson 1979, Drent \& Daan 1980, Birt et al. 1987, Lewis et al. 2001b). However, to our knowledge, no study has simultaneously quantified the effects of daily, seasonal and interannual environmental conditions and breeding density on seabird breeding diet.

Here, we used 3 decades of diet data from European shags Phalacrocorax aristotelis (hereafter shag), breeding at a North Sea colony, to quantify dietary trends and test associations with annual, seasonal and daily environmental conditions and annual breeding population density. The North Sea has warmed rapidly, increasing by $0.037^{\circ} \mathrm{C} \mathrm{yr}^{-1}$ between 1982 and 2012 (Høyer \& Karagali 2016). Associated with this warming there have been marked changes in the abundance, distribution and phenology of many species at multiple trophic levels, including a switch in the dominant zooplankton species and a northwards shift in many fish species (Beaugrand 2004, Perry et al. 2005, Hiddink \& ter Hofstede 2008, Burthe et al. 2012). Large parts of the North Sea exhibit a 'wasp-waist' ecosystem (Cury et al. 2000), characterised by high diversity at upper- and lowertrophic levels, but low diversity of mid-trophic species, dominated by a small planktivorous shoaling fish - the lesser sandeel Ammodytes marinus (hereafter sandeel). Sandeels have a clear annual cycle whereby spawning occurs in late winter, and the 1+ group (sandeels hatched prior to the current year) are active in the water column during spring (April/ May) before burying in sandy sediments, while the 0 group (young-of-the-year) become available from June onwards following metamorphosis (Wright \& Bailey 1996). Some sandeel populations have shown a decrease in abundance, size, growth rates, energetic quality and shifting phenology in recent decades linked to rising sea temperatures and associated changes in their copepod prey (Arnott \& Ruxton 2002, Wanless et al. 2004, van Deurs et al. 2009, Frederiksen et al. 2011, Rindorf et al. 2016). The sandeel is the principal prey of many top predators, including the majority of seabirds in the region (Furness \& Tasker 2000), and dramatic declines in several seabird breeding populations have been attributed to reduced sandeel availability (Mitchell et al. 2004, Daunt \& Mitchell 2013).

Previous analyses of shag diet from the early period of this study demonstrated that, during the 
breeding season, this population consisted of sandeel specialists (Harris \& Wanless 1991, 1993, Daunt et al. 2008). However, diet varies substantially across the species' range, including large numbers of Gadidae and Gobiidae taken by some populations, suggesting that shags adopt a flexible foraging strategy to exploit available prey (Steven 1933, Furness 1982, Cosolo et al. 2011, Hillersøy \& Lorentsen 2012). Such flexibility could have resulted in a change in diet composition and diversity over the past 3 decades if sandeels have become scarcer and/or lessened in energetic value relative to alternative prey, or non-sandeel prey have become more common and/or increased in energetic value. Furthermore, although shags can extract sandeels from the sand (Watanuki et al. 2008), they can achieve high profitability from pelagic shoals of 0 group sandeel when they become available late in the season (Wanless et al. 1998). Thus, a seasonal shift to the 0 group might be expected, in line with blacklegged kittiwakes Rissa tridactyla, Atlantic puffins Fratercula arctica and common guillemots Uria aalge breeding at the same colony (Lewis et al. 2001a, Wanless et al. 2004, Daunt et al. 2008). In addition, foraging and flight performance of shags is affected by daily wind conditions (Daunt et al. 2006, 2014, Lewis et al. 2015, Kogure et al. 2016). Accordingly, short-term weather may be important in determining shag diet composition if wind affects catchability or availability of different prey. Finally, the study population has declined from 1524 pairs in 1985 to 338 pairs in 2014, which may have affected diet composition through changes in intra-specific competition. Therefore, this population provides an excellent study system to test the dietary response of a top predator to interannual, seasonal and daily variability in environmental conditions and population density.

Our specific aims were to (1) test whether the mean annual proportion of sandeel in the shag's diet and mean length of sandeels (an index of energetic value) has changed over the last $30 \mathrm{yr}$ and, if so, whether diet diversity has increased, (2) quantify whether diet composition is related to annual indices of prey availability (sea surface temperature and copepod abundance), (3) test whether there is a seasonal pattern in diet composition such that the proportion of 0 group sandeels is higher later in the season, (4) quantify the relationship between short-term weather conditions and diet composition, and (5) investigate the extent to which density of conspecifics is a determinant of annual diet composition.

\section{MATERIALS AND METHODS}

\section{Quantifying diet}

The study was conducted between 1985 and 2014 on the Isle of May National Nature Reserve, Firth of Forth, southeast Scotland (56 $\left.{ }^{\circ} 11^{\prime} \mathrm{N}, 02^{\circ} 33^{\prime} \mathrm{W}\right)$. European shag Phalacrocorax aristotelis diet was quantified during the chick-rearing period (April to July) in each year using a standardised methodology (Harris \& Wanless 1991). During routine fieldwork, chicks and adults occasionally regurgitated food. Regurgitates were collected, visually inspected by experienced observers to determine the approximate proportional prey composition, weighed and then frozen. Previous work has shown that food regurgitated by adults at the nest is predominantly destined for the brood (Wanless et al. 1993), so we assumed that adult samples represented chick diet and pooled them with chick samples in the analysis (chick: $\mathrm{n}=727$; adult: $\mathrm{n}=112$; unknown: $\mathrm{n}=24$ ).

Samples were subsequently thawed then placed in a saturated solution of biological washing powder (Biotex@) and heated at 40 to $50^{\circ} \mathrm{C}$ for a minimum of $5 \mathrm{~h}$, until all soft tissue was digested. The residual hard parts (e.g. fish otoliths, vertebrae and mouth parts, cephalopod beaks, and crustacean exoskeletons) were then identified to the lowest possible taxon using keys in Härkönen (1986) and Watt et al. (1997). Some items were identified to species level, but this was not possible in most cases. Therefore, fish prey were grouped by family, and molluscs, annelids and arthropods, which together contributed little to the diet $(3 \%$ combined biomass over all years), by phylum. Otoliths were counted, and measured under a binocular microscope $(25 \times$ magnification). Sandeels Ammodytes spp. (virtually all those identified were lesser sandeel $A$. marinus so hereafter sandeels refer to this species) were aged as 0 or 1+ group using otolith macrostructure (ICES 1995). We calculated the biomass proportion of each fish prey type in each regurgitate by converting otolith lengths into fish weights in 2 steps. First, fish lengths were estimated from relationships with otolith length. For 0 and 1+ group sandeels, we used regression equations based on an annual sample of intact fish collected by mist-netting Atlantic puffins Fratercula arctica at this colony over the same period shag diet was sampled (Lewis et al. 2001a, updated). For other species, we used published otolith length/fish length regression equations (Lewis et al. 2003, see Table S1 in the Supplement at www.int-res.com/ articles/suppl/m583p227_supp.pdf). Second, we used 
species-specific length/mass regression equations to calculate fish weight and, therefore, biomass proportion of each prey type in each sample (Lewis et al. 2003, Table S1). Where no bones were present following digestion, the initial visual assessments of biomass proportions were used. This approach was appropriate as there was very close accordance between these 2 methods in samples where both were available $\left(\mathrm{r}^{2}\right.$ of arcsine-transformed proportions of sandeels to non-sandeels $=0.96 ; n=185$ ). Only mean annual biomass proportions were available for 1989 (individual sample data were lost in a fire).

\section{Dietary response variables}

Quantifying diet from regurgitates may involve biases due to differential rates of digestion, egestion and detectability of different prey types (Barrett et al. 2007). We focussed on analysing patterns of change and association with environmental covariates of relative proportions of different prey types, because such analyses are robust to such biases. However, analysing biomass proportions can lead to problems of interpretation, because a change in one type cannot readily be distinguished from an opposite change in the others. Interpretation is particularly challenging where a small number of prey types dominate, as in our study where $83 \%$ of the diet comprised 2 prey types. To overcome this, we undertook analyses of the relative proportions of different pairs of prey types in a hierarchical manner. First, we calculated the proportion of all sandeels relative to all other prey. Next, we calculated the proportion of $1+$ group relative to 0 group sandeels. Finally, for each nonsandeel prey type, we calculated the proportion relative to all other non-sandeel prey, since the nonsandeel component was not dominated by a small number of prey types. This calculation was possible with 3 non-sandeel prey types: Pholidae, Gadidae and Callionymidae. The remaining prey types (Cottidae, Pleuronectidae, Clupeidae, Labridae, Gobiidae, Zoarcidae, Annelida, Blenniidae, Mollusca, Arthropoda, Lotidae and Syngnathidae) were rare, representing $<0.05$ of mean biomass proportion across all years combined, and hence were not analysed individually relative to other non-sandeel prey.

Diet diversity was quantified by calculating the number of prey types in each regurgitate sample, which we refer to as sample-level prey richness. As prey richness is a count, it will systematically be higher at the aggregate, annual level than the sample level (sample-level prey richness range $=1$ to 7 ; annual prey richness range $=1$ to 12 ), so we considered both sample-level and annual level prey richness (i.e. pooling information from all samples in each year). As with diet proportions, we analysed trends and environmental drivers of sample-level prey richness (trends only for annual prey richness), which we considered robust to any biases associated with differential probability of presence in different prey types in regurgitated samples.

\section{Environmental covariates}

\section{Annual sandeel proxies}

As there are no long-term abundance data for the local sandeel population upon which Isle of May shags feed, we utilised 3 environmental proxies of sandeel availability.

Sea Surface Temperature (SST): SST affects sandeel recruitment via the bottom-up effects of temperature on the availability of key copepod prey (Wright \& Bailey 1993, Arnott \& Ruxton 2002, van Deurs et al. 2009). Monthly SST data were obtained from the German 'Bundesamt fur Seeschifffart und Hydrographie' (www.bsh.de). Following Frederiksen et al. (2004), we calculated the mean of February and March SST for an inshore area surrounding the Isle of May (bounded by ca. $56^{\circ} 0^{\prime}$ to $56^{\circ} 4^{\prime} \mathrm{N}$, and $2^{\circ} 7^{\prime}$ to $2^{\circ} 3^{\prime} \mathrm{W}$ ), overlapping with the summer foraging range of this population (Bogdanova et al. 2014).

Calanus abundance: calanoid copepods, in particular the eggs and nauplii of Calanus finmarchicus, are of key importance to survival probability of early life stages of sandeels (Macer 1966, Arnott \& Ruxton 2002, van Deurs et al. 2009). We analysed 1597 samples from the continuous plankton recorder (see Reid et al. 2003 for an overview) taken from a bounding box surrounding the Isle of May $\left(55^{\circ}\right.$ to $\left.58^{\circ} \mathrm{N}, 3^{\circ} 0^{\circ} \mathrm{E}\right)$, between 1984 and 2014. This box is larger than the summer foraging range of the study population, but ensured there were sufficient data for the analysis. We included 2 measures of Calanus: C. finmarchicus (stages V to VI) abundance (as a proxy for $C$. finmarchicus egg production; van Deurs et al. 2009) and Calanus nauplii abundance (for all species combined, as species-specific abundances were unavailable). For each measure, we calculated mean monthly abundance from February to May, since these months constitute the principal period of larval sandeel feeding (Wright \& Bailey 1996, van Deurs et al. 2009).

Lagged covariates: the abundance of 1+ group sandeels is dependent on conditions experienced as 
0 group fish in the previous year (Arnott \& Ruxton 2002). We therefore considered SST, C. finmarchicus (stages V to VI) abundance and Calanus nauplii abundance lagged by $1 \mathrm{yr}$ as indices of the abundance of $1+$ sandeel in the current year.

Seasonal prey availability

$1+$ group sandeels are active in the water column each spring, while 0 group sandeels become available in early summer following metamorphosis (Macer 1966, Winslade 1974, Wright \& Bailey 1993). We therefore tested whether there was a seasonal trend in diet composition from $1+$ to 0 group sandeels by including the date of sample collection in the analyses, which we refer to hereafter as day-of-year.

\section{Daily conditions}

The flight and diving performance of shags is affected by local weather, in particular wind conditions (Daunt et al. 2006, Lewis et al. 2015, Kogure et al. 2016) and potentially rainfall, which in turn may affect diet composition as previously shown in other seabirds (Finney et al. 1999, Stienen et al. 2000). Therefore, we used hourly wind speed $\left(\mathrm{m} \mathrm{s}^{-1}\right)$ and daily rain $(\mathrm{mm})$ data obtained from the Leuchars weather station $\left(56^{\circ} 23^{\prime} \mathrm{N}, 2^{\circ} 52^{\prime} \mathrm{W}\right)$, ca. $28 \mathrm{~km}$ from the study site (http://badc.nerc.ac.uk), to calculate mean daily wind speed $\left(\mathrm{m} \mathrm{s}^{-1}\right)$ and total daily rainfall $(\mathrm{mm})$ on the day of sample collection.

\section{Population density}

To account for potential density dependent effects, we fitted annual breeding population size. This was estimated using standardised protocols (Walsh et al. 1995; mean $\pm \mathrm{SD}=786 \pm 494$ pairs; range $=201$ to 1916).

\section{Statistical analysis}

Diet trends

All statistical analyses were conducted using $\mathrm{R}$ programming software ( $\mathrm{R}$ Development Core Team 2016) with figures created using the 'ggplot2' package (Wickham 2009). Trends in sample-level biomass proportions and prey richness were tested using gen- eralised linear mixed models (GLMMs) fitted using the penalized quasi-likelihood methods in the 'glmmPQL' function ('MASS' package; Venables \& Ripley 2002), which automatically accounts for overdispersion. This method was chosen due to irresolvable model convergence issues relating to analysis of the sample-level diet data encountered using the 'glmer' function in the 'Ime4' package (Bates et al. 2014). However, information theoretic approaches, such as Akaike's Information Criterion, are not available using 'glmmPQL'; hence, model selection was conducted via backwards stepwise deletion. Binomial and Poisson models with logit- and log-link functions, respectively, were fitted for biomass proportions and prey richness, respectively. We subtracted 1 from prey richness, to improve the plausibility of the assumption that the variable has a Poisson distribution. However, model results and plots are presented on the original, unadjusted scale. In each analysis, the fixed effect of year was centred on zero (by subtracting mean year from each value) and rescaled (by dividing the centred value by the standard deviation of year). Visual inspection of the data suggested that diet trends may have been non-linear, so we fitted a linear and quadratic effect of year. To account for repeat sampling, we fitted a categorical, random effect of year.

To identify trends in annual prey richness, where there was 1 estimate $\mathrm{yr}^{-1}$, we fitted a GLMM with a Poisson error family using the 'glmer' function, subtracting 1 from each value. In this instance, model selection was conducted using Akaike's Information Criterion corrected for small sample sizes $\left(\mathrm{AIC}_{\mathrm{c}}\right)$, with the best supported model considered to be the one with the lowest $\mathrm{AIC}_{\mathrm{c}}$ unless others were within 2 $\mathrm{AIC}_{\mathrm{c}}$ values, in which case they were considered to have similar levels of support (Burnham \& Anderson 2002). A global model, containing both a linear and a quadratic numeric fixed effect of year, was fitted to investigate trends along with a categorical, random effect of year to account for overdispersion. In addition, we weighted each annual prey richness value by the number of samples per year and included a fixed effect of $\log$ (no. of samples $\mathrm{yr}^{-1}$ ) to account for any systematic change in prey richness with annual sample size.

Linear mixed effects models (LMMs) were fitted to individual estimated fish lengths using the 'Imer' function in the 'Ime4' package, with model selection conducted using $\mathrm{AIC}_{\mathrm{c}}$. Estimated fish length was only available from 1989 to 2014 and could only be modelled for $1+$ and 0 group sandeels, as other prey occurred too infrequently in the first half of the study. 
We fitted year, age class and a year $\times$ age class interaction as fixed effects to test whether any trend in estimated length varied with age class, and a categorical, random effect of year to account for repeat sampling. The 'dredge' function in the 'MuMIn' package (v.1.15-6; Barto 2016) was used to identify the best supported model for both annual prey richness and estimated fish length, based on $\mathrm{AIC}_{\mathrm{C}}$.

\section{Environmental covariates}

Effects of the environmental covariates (annual measures of SST, SST in $t-1$, Calanus nauplii abundance, Calanus nauplii abundance in $t-1, C$. finmarchicus abundance and $C$. finmarchicus abundance in $t-1$, day of year, mean daily wind, total daily rain, and breeding population size) on samplelevel biomass proportions and prey richness were quantified using GLMMs in the 'glmmPQL' function. This analysis was selected because of the same irresolvable model convergence issues experienced in the analysis of trends in these variables. We had no biological a priori reason to test for interaction terms, and therefore our analysis considered main effects only. To test for collinearity between covariates, we calculated Pearson's correlation coefficients. None were strongly collinear (max. coefficient $=0.45$; see Table S2 in the Supplement) and hence all covariates were retained in the modelling process. A global model was fitted containing all potential fixed effects, and a random, categorical effect of year; model selection was the same as for the trends analysis of biomass proportions and sample-level prey richness.

Previous analyses have identified trends in environmental parameters within the North Sea (Burthe et al. 2012), and the co-occurrence of trends in both dependent and independent variables may lead to spurious results (Grosbois et al. 2008). Accordingly, we calculated Pearson's correlation coefficients and associated p-values between all of the covariates and numeric year, and found temporal trends in some of the explanatory covariates (see 'Results'). Therefore, as a supplementary analysis, we fitted year into the final dietary response models as a numeric fixed effect to remove any temporal effects in the response variable, and re-ran the model selection. Year was retained in the final model for all analyses, irrespective of whether a significant effect was found. The resulting models ('detrended models') were compared to the models without detrending ('non-detrended models'). We cannot exclude the possibility that where variables were only significant in non-detrended models, the effect was due to a correlation with a third variable that is also showing a trend over time, and such relationships were therefore treated with caution. The results from the non-detrended models are given in the main text and those from the detrended models in the Supplement.

\section{RESULTS}

\section{Diet composition}

A total of 863 diet samples were collected between 1985 and 2014 ( $\mathrm{n}=29 \mathrm{yr}$ median: 26 samples $\mathrm{yr}^{-1}$; range: 4 to $69 ; \mathrm{n}=425$ sample days; median: $14 \mathrm{~d} \mathrm{yr}^{-1}$; range: 2 to 16 ; median day-of-year: 182; range: 82 to 228). A total of 16 prey types were recorded, the most common being lesser sandeel Ammodytes marinus, which represented $0.83 \pm 0.35$ (mean proportion \pm SD) of total biomass and occurred in $88 \%$ of samples (Table 1). $1+$ and 0 group sandeels contributed $0.70 \pm$ 0.42 and $0.12 \pm 0.30$, respectively, to total biomass, and occurred in 78 and $25 \%$ of samples, respectively. Other prey included Pholidae $(0.05 \pm 0.19$ of total biomass, $8 \%$ of samples), Gadidae $(0.04 \pm 0.17 ; 9 \%)$, Callionymidae (dragonets; $0.02 \pm 0.17 ; 5 \%$ ) and Cottidae $(0.02 \pm 0.09 ; 2 \%)$. Clupeidae, Pleuronectidae, Labridae, Zoarcidae, Gobiidae, Annelida, Arthropoda, Mollusca, Blenniidae, Lotidae and Syngnathidae each contributed $0.01 \pm 0.10$ or less to total biomass, with $0.01 \pm 0.10$ of the total biomass unidentifiable (Table 1). Overall, the estimated mean $( \pm \mathrm{SD})$ length of sandeels was $101.10 \pm 27.35 \mathrm{~mm}$, with $1+$ and 0 group sandeels being $117.30 \pm 13.46$ and $74.74 \pm$ $20.20 \mathrm{~mm}$, respectively.

\section{Annual diet trends}

The proportion of sandeel relative to all other prey types declined significantly over the study period, from 0.99 in 1985 to 0.51 in 2014 (Fig. 1a, Tables 2 \& S3 in the Supplement at www.int-res.com/articles/ suppl/m583p227_supp.pdf). However, there was no change in the relative proportion of $1+$ group to 0 group sandeel (Tables 2 \& S3, Fig. 1a). There was no trend in the proportion of Pholidae or Gadidae relative to other non-sandeel prey (Tables 2 \& S3, Fig. 1b), but Callionymidae showed a significant decrease in proportion relative to other non-sandeel prey, from 0.57 in 1985 to 0.02 in 2014 (Table 2, Fig. 1b). There was a significant linear increase in samplelevel prey richness from 1.03 in 1985 to 1.50 in 2014 
Table 1. Mean $( \pm \mathrm{SD})$ biomass proportion, number and percentage of samples for each prey class of European shag diet pooled over the entire study. Range of pooled annual mean values are presented. The sum of $1+$ and 0 group sandeels is less than total sandeels since $1 \%$ could not be aged

\begin{tabular}{|lrrc|}
\hline Prey & $\begin{array}{c}\text { Biomass } \\
\text { (mean } \pm \text { SD) }\end{array}$ & Range & $\begin{array}{c}\text { No. of } \\
\text { samples (\%) }\end{array}$ \\
\hline Sandeel (mainly Ammodytes marinus) & $0.83 \pm 0.35$ & $0.28-1.00$ & $734(88)$ \\
$1+$ group sandeel & $0.70 \pm 0.42$ & $0.01-1.00$ & $650(78)$ \\
0 group sandeel & $0.12 \pm 0.30$ & $<0.01-0.94$ & $211(25)$ \\
Pholidae (gunnels) & $0.05 \pm 0.19$ & $<0.01-0.40$ & $69(8)$ \\
Gadidae (cod fishes) & $0.04 \pm 0.17$ & $<0.01-0.27$ & $79(9)$ \\
Callionymidae (dragonets) & $0.02 \pm 0.12$ & $<0.01-0.08$ & $18(2)$ \\
Cottidae (cottids) & $0.02 \pm 0.09$ & $<0.01-0.22$ & $39(5)$ \\
Unidentifiable prey & $0.01 \pm 0.10$ & $<0.01-0.12$ & $16(2)$ \\
Pleuronectidae (right-eyed flounders) & $0.01 \pm 0.08$ & $<0.01-0.08$ & $28(3)$ \\
Clupeidae (mainly herring and sprat) & $0.01 \pm 0.08$ & $<0.01-0.20$ & $35(4)$ \\
Labridae (wrasses) & $<0.01 \pm 0.06$ & $<0.01-0.04$ & $14(2)$ \\
Gobiidae (gobies) & $<0.01 \pm 0.04$ & $<0.01-0.06$ & $19(2)$ \\
Zoarcidae (eelpouts) & $<0.01 \pm 0.04$ & $<0.01-0.03$ & $6(1)$ \\
Annelida (mainly polychaete worms) & $<0.01 \pm 0.02$ & $<0.01-0.03$ & $6(1)$ \\
Blenniidae (blennies) & $<0.01 \pm 0.01$ & $<0.01-0.02$ & $2(<1)$ \\
Mollusca (molluscs) & $<0.01 \pm 0.01$ & $<0.01-0.01$ & $17(2)$ \\
Arthropoda (mainly Crustacea) & $<0.01 \pm 0.01$ & $<0.01-0.01$ & $20(2)$ \\
Lotidae (rocklings) & $<0.01 \pm 0.01$ & $<0.01-0.01$ & $4(<1)$ \\
Syngnathidae (pipefishes) & $<0.01$ & $<0.01-<0.01$ & $5(1)$ \\
\hline
\end{tabular}

(Tables 2 \& S3). There was also a marked linear increase in annual prey richness from 1.32 in 1985 to 11.05 in 2014 (Table 3, Fig. 2). There was no evidence of a quadratic relationship in the trends in biomass proportions, sample-level prey richness or annual prey richness (Tables 3 \& S3).

Estimated mean length of sandeels declined by $12 \%$ over the study period, from $104.5 \mathrm{~mm}$ in 1989 to $92.0 \mathrm{~mm}$ in 2014 (Table 3, Fig. 3). There was an interaction between year and age class, such that the decline in estimated length was more marked in 0 group sandeel $(22.6 \%$ decline from $87.1 \mathrm{~mm}$ in 1989 to $67.4 \mathrm{~mm}$ in 2014) than in 1+ group sandeel $(4.5 \%$ decline from $121.9 \mathrm{~mm}$ in 1989 to $116.4 \mathrm{~mm}$ in 2014; Table 3, Fig. 3).

a

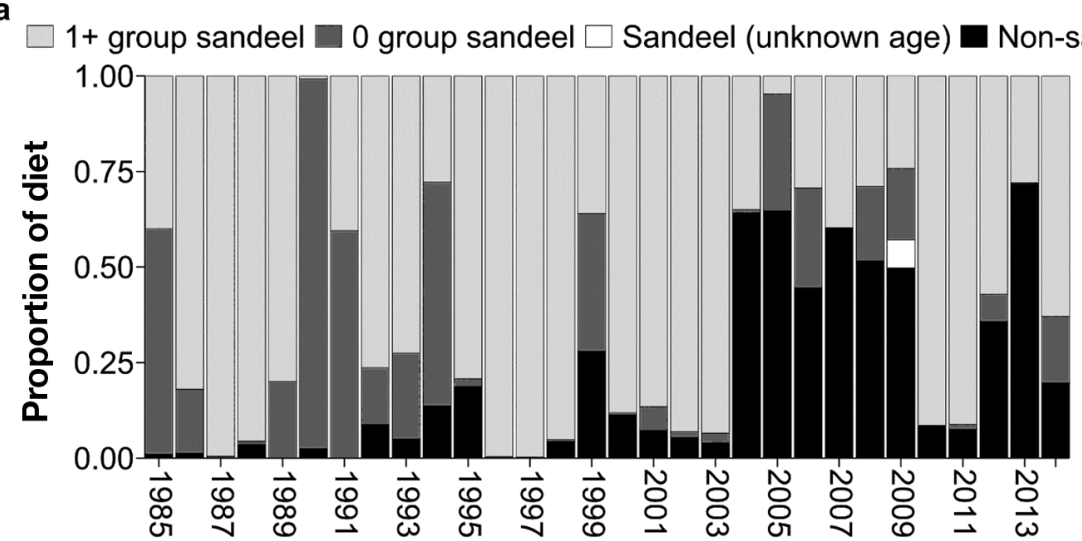

b

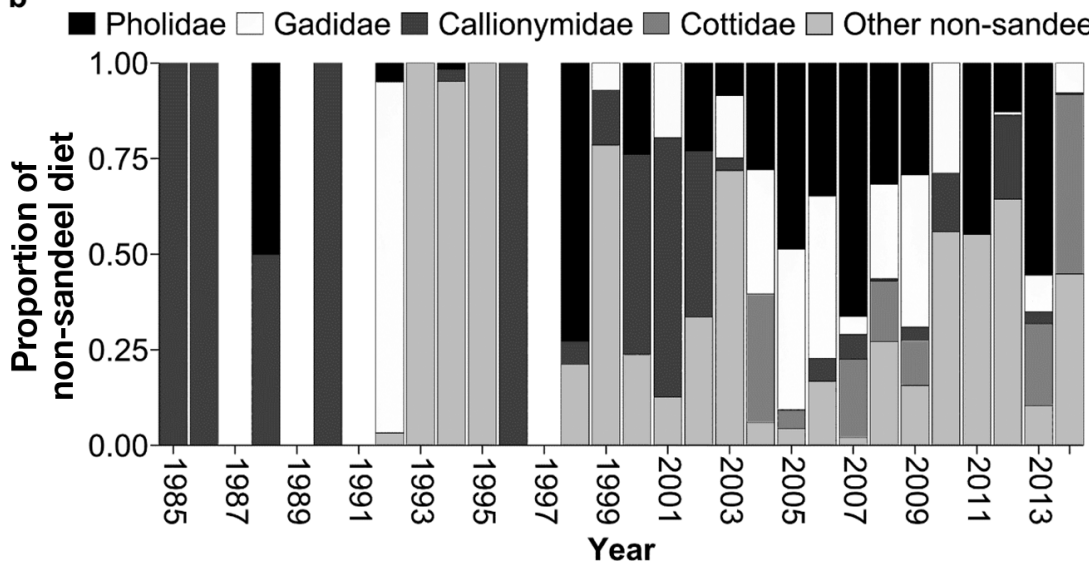

Fig. 1. (a) Interannual variation in biomass proportion (mean across samples in each year) of sandeel by age class and nonsandeel prey in the diet of European shag from 1985 to 2014. (b) Interannual variation in biomass proportion (mean across samples in each year) of non-sandeel prey in the non-sandeel component of the diet from 1985 to 2014 . Sandeel contributed $100 \%$ of the diet in 1987, 1989, 1991 and 1997 
Table 2. Estimates $( \pm \mathrm{SE})$ and $t$ - and $\mathrm{p}$-values for linear trends in European shag diet proportions. Year was standardized and values presented are on the logit scale

\begin{tabular}{|lrrrr|}
\hline Response variable & Estimate & SE & $t$ & $\mathrm{p}$ \\
\hline Sandeel relative to non-sandeel prey & -14.49 & 3.22 & -4.50 & $<0.001$ \\
1+ relative to 0 group sandeel & 4.65 & 5.42 & 0.86 & 0.398 \\
Pholidae relative to other non-sandeel prey & 5.48 & 4.17 & 1.31 & 0.202 \\
Callionymidae relative to other non-sandeel prey & -13.91 & 4.84 & -2.87 & 0.008 \\
Gadidae relative to other non-sandeel prey & -0.10 & 4.69 & -0.02 & 0.984 \\
Sample-level prey richness & 12.09 & 2.37 & 5.09 & $<0.001$ \\
\hline
\end{tabular}

$6.8^{\circ} \mathrm{C}$ ). This decrease was relatively constant until ca. $6^{\circ} \mathrm{C}$; the proportion of $1+$ group dropped rapidly when temperature was higher (Table 5, Fig. 4a). A greater proportion of Pholidae relative to other non-sandeel prey was associated with higher SST in the previous year, with a relatively steep but consistent increase

\section{Environmental covariates}

Over the study period, SST and Calanus nauplii abundance increased significantly, Calanus finmarchicus abundance and shag breeding population size declined and date of sample collection advanced (Table 4). Mean daily wind speed and rain did not show a trend over time (Table 4).

\section{Annual effects}

The proportion of $1+$ group relative to 0 group sandeel was higher when SST in February and March the previous year was lower $\left(1.00\right.$ at $4.5^{\circ} \mathrm{C}$ vs. 0.67 at from 0.04 at $4.9^{\circ} \mathrm{C}$ to 0.57 at $6.8^{\circ} \mathrm{C}$ (Table 5, Fig. $4 \mathrm{~b}$ ). Sample-level prey richness increased with SST in the previous year, from 1.05 at $4.5^{\circ} \mathrm{C}$ to 1.35 at $6.8^{\circ} \mathrm{C}$ (Table 5, Fig. 5a). Years with higher abundance of $C$. finmarchicus were associated with a lower proportion of Pholidae (Table 5, Fig. 4c). The proportion of Callionymidae in the diet relative to other non-sandeel prey was greater when the abundance of Calanus nauplii, both in the current and preceding year, was higher (Table 5, Fig. 4d,e). Years with a high abundance of Calanus nauplii were associated with a reduction in prey richness (Table 5, Fig. 5b). None of the fixed effects were significant determinants of the proportion of Gadidae in the diet relative to other nonsandeel prey. No other annual effects were significant.

Table 3. Model selection for annual European shag dietary prey richness (generalized linear mixed model; GLMM) and sandeel length (linear mixed effect model; LMM). Model structure, fixed effects, estimates ( \pm SE), $z$-value (annual prey richness), $t$-value (sandeel length), number of parameters $(k)$, difference in Akaike's Information Criterion corrected for small sample sizes compared to top model $\left(\Delta \mathrm{AIC}_{\mathrm{c}}\right)$ and $\mathrm{AIC}_{\mathrm{c}}$ weight relative to other models $\left(\omega_{i}\right)$, are displayed. Age class values are presented relative to the $1+$ group category. $i=$ intercept. $\log ($ sample $)=\log \left(\right.$ number of samples year $\left.{ }^{-1}\right)$. Best supported models are highlighted in bold

\begin{tabular}{|c|c|c|c|c|c|c|c|c|}
\hline Response & Model & Fixed effect & Estimate & $\mathrm{SE}$ & $z$ or $t$ & $k$ & $\Delta \mathrm{AIC}_{\mathrm{C}}$ & $\omega_{i}$ \\
\hline \multirow{9}{*}{$\begin{array}{l}\text { Annual prey } \\
\text { richness }\end{array}$} & \multirow[t]{3}{*}{$i+$ Year $+\log ($ sample $)$} & & & & & \multirow[t]{3}{*}{3} & \multirow[t]{3}{*}{0.00} & \multirow[t]{3}{*}{0.78} \\
\hline & & Year & 1.63 & 0.49 & 3.32 & & & \\
\hline & & $\log ($ sample) & -0.51 & 0.70 & -0.73 & & & \\
\hline & \multirow[t]{4}{*}{$i+$ Year + Year $^{2}+\log ($ sample $)$} & & & & & \multirow[t]{4}{*}{4} & \multirow[t]{4}{*}{2.82} & \multirow[t]{4}{*}{0.19} \\
\hline & & Year & 1.64 & 0.49 & 3.33 & & & \\
\hline & & Year $^{2}$ & -0.19 & 0.54 & -0.35 & & & \\
\hline & & $\log ($ sample) & -0.53 & 0.72 & -0.73 & & & \\
\hline & \multirow{2}{*}{$i+\log ($ sample $)$} & & & & & \multirow[t]{2}{*}{2} & \multirow{2}{*}{6.67} & \multirow[t]{2}{*}{0.03} \\
\hline & & $\log ($ sample) & -0.06 & 0.84 & -0.08 & & & \\
\hline \multirow{10}{*}{ Sandeel length } & \multirow[t]{3}{*}{ (Year $\times$ Age class $)$} & Year & -5.33 & 1.85 & -2.89 & \multirow{3}{*}{4} & \multirow{3}{*}{0.00} & \multirow{3}{*}{1.00} \\
\hline & & Age class (1+ group) & 41.81 & 0.47 & 89.80 & & & \\
\hline & & Year $\times$ Age class $(1+$ group $)$ & 3.84 & 0.44 & 8.72 & & & \\
\hline & \multirow[t]{3}{*}{$i+$ Year + Age class } & & & & & \multirow[t]{3}{*}{3} & \multirow[t]{3}{*}{73.60} & \multirow[t]{3}{*}{0.00} \\
\hline & & Year & -3.53 & 1.76 & -2.00 & & & \\
\hline & & Age class (1+ group) & 42.65 & 0.46 & 93.34 & & & \\
\hline & $i+$ Age class & A se class $(1+$ oroun & 4264 & 0.46 & 0327 & 2 & 75.34 & 0.00 \\
\hline & \multirow{3}{*}{$i+Y e a r$} & 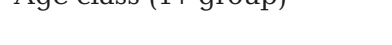 & & & & 1 & 6328.10 & 0.00 \\
\hline & & & & & & \multirow[t]{2}{*}{2} & \multirow[t]{2}{*}{6329.90} & \multirow[t]{2}{*}{0.00} \\
\hline & & Year & -1.37 & 3.48 & -0.39 & & & \\
\hline
\end{tabular}




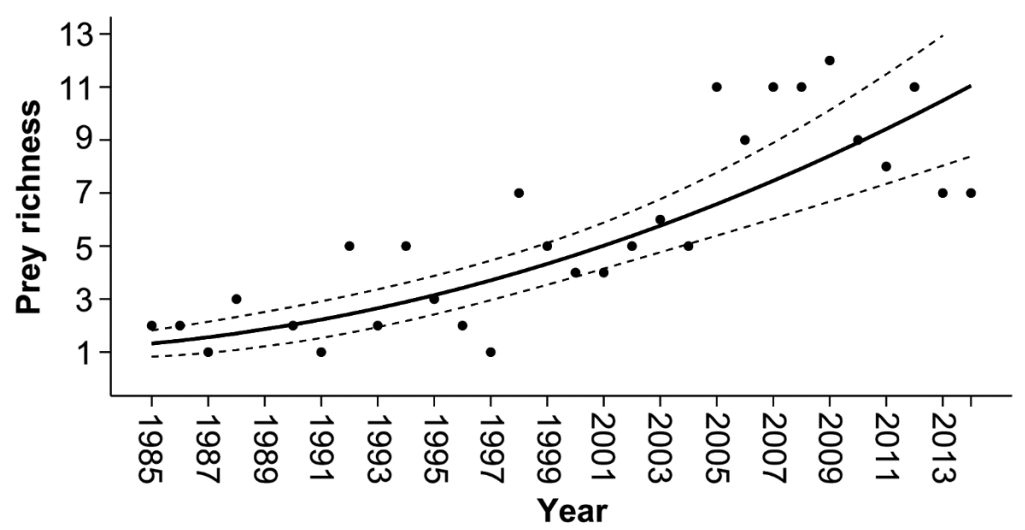

Fig. 2. Interannual variation in annual prey richness in the diet of European shag from 1985 to 2014 . Fitted line ( $\pm 95 \%$ CI) shows linear relationship on the log(expected value), which when plotted on the untransformed count data appears as a quadratic relationship due to the Poisson distribution of the data

\section{Seasonal and daily effects}

There was a seasonal decline in the proportion of $1+$ group relative to 0 group sandeel, from a predicted value of 1.00 in March to 0.24 by August, driven by a sharp decline at the start of July (Table 5 , Fig. 4f). Furthermore, the proportion of sandeels relative to other prey types was lower on windier days (0.92 at $2 \mathrm{~m} \mathrm{~s}^{-1}$ vs. 0.75 at $24 \mathrm{~m} \mathrm{~s}^{-1}$; Table 5, Fig. $4 \mathrm{~g}$ ). No other daily or seasonal effects were significant.

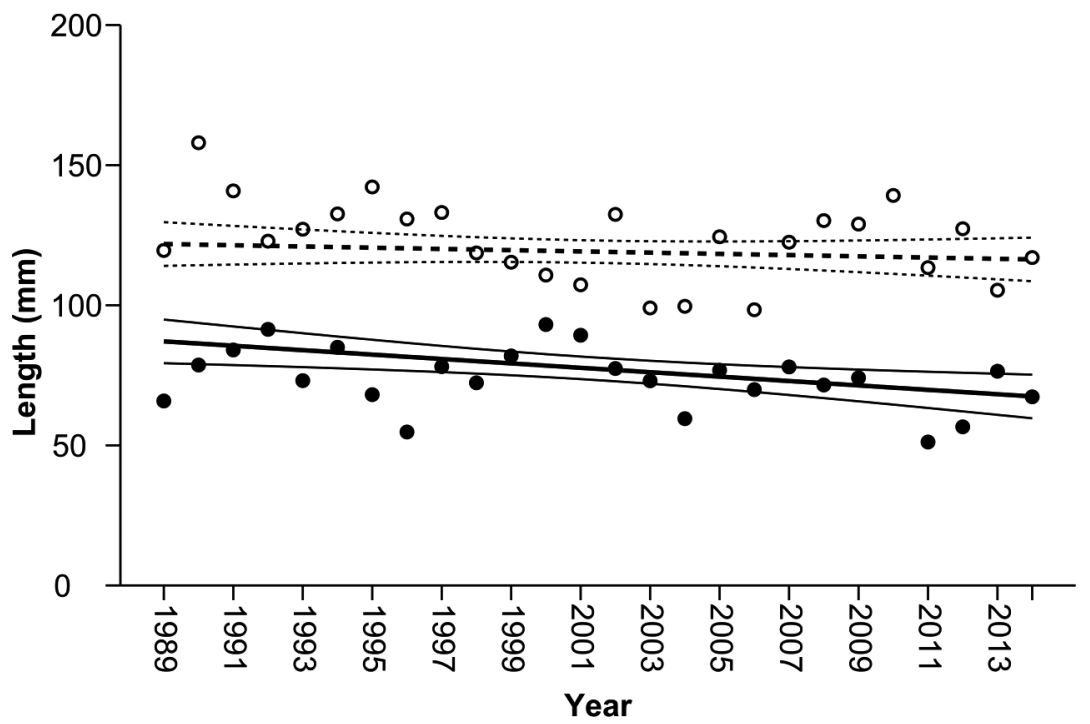

Fig. 3. Interannual variation in sandeel length for $1+$ group (०) and 0 group (•) sandeel from 1989 to 2014. Solid lines indicate the fitted line and confidence intervals for 0 group sandeel. Dashed line indicates the fitted line and confidence intervals for 1+ group sandeel. Analysis was conducted on individual fish length data (predicted from otoliths), but here we present annual mean values for each age class. Data were not available from 1985 to 1988 because those records were lost in a fire

\section{Population density effects}

The proportion of sandeel relative to other prey was greater when the breeding population size was larger, from a predicted value of 0.99 at 1916 pairs to 0.64 at 201 pairs (Table 5, Fig. 4h). Furthermore, higher breeding population size was associated with an increase in Callionymidae in the diet, ranging from 0.46 at 1634 pairs to 0.03 at 201 pairs (Table 5, Fig. 4i). Samplelevel prey richness was also lower at higher breeding population sizes, ranging from a predicted value of 1.29 at 201 pairs to 1.03 at 1916 pairs (Table 5, Fig. 5c). However, the detrending analysis removed the effect of population size from all analyses and thus this effect should be treated with caution (see Table S4 in the Supplement).

\section{DISCUSSION}

Using a dataset spanning 3 decades, we quantified long-term European shag Phalacrocorax aristotelis dietary trends and tested the effects of environmental conditions on diet composition at interannual, seasonal and daily temporal scales. We found a marked reduction in the proportion of lesser sandeel Ammodytes marinus and a concurrent prey diversification over the study period, with a much wider range of prey items now exploited. We also identified a reduction in the size of both $1+$ and 0 group sandeels in the diet. Overall, the diet showed both immediate and lagged responses to a suite of environmental conditions operating over a range of temporal scales, from days to decades. Furthermore, our results suggest that diet diversification over time was linked to the trend in SST in our study system. Thus, the predicted increases in climatic mean and variability at higher latitudes may lead to a further generalism in shag diet in the future.

\section{Diet trends}

Until the early 2000s, shags on the Isle of May fed their young mainly sandeels (Harris \& Wanless 1991, 1993, Daunt et 
Table 4. Pearson's correlation coefficients (r) and associated $\mathrm{p}$-values ( $\mathrm{p}$ ) for correlations between explanatory covariates and year with respect to European shag diet. Maximum and minimum values are displayed for each variable

\begin{tabular}{|lccrr|}
\hline Covariate & Min. & Max. & $\mathrm{r}$ & $\mathrm{p}$ \\
\hline Sea surface temperature & 4.5 & 6.75 & 0.44 & $<0.001$ \\
Calanus nauplii abundance & 0.0 & 55.1 & 0.14 & $<0.001$ \\
C. finmarchicus abundance & 0.3 & 19.3 & -0.12 & $<0.001$ \\
Day-of-year & 82 & 228 & -0.50 & $<0.001$ \\
Mean daily wind $\left(\mathrm{m} \mathrm{s}^{-1}\right)$ & 2.1 & 23.7 & 0.06 & 0.078 \\
Total daily rain (mm) & 0.0 & 50.7 & -0.01 & 0.864 \\
Breeding population size & 201 & 1916 & -0.57 & $<0.001$ \\
\hline
\end{tabular}

al. 2008), but chick diet has changed substantially over the last $15 \mathrm{yr}$, with a decline in their main prey, sandeel, and an increase in diet diversity. Theory suggests that diet diversifies when predominant prey become scarce and/or lessen in profitability (Stephens \& Krebs 1986), and empirical evidence in other seabird studies supports this (Croxall et al. 1999, Cosolo et al. 2011, Gaston \& Elliott 2014). Shags exploit a wide range of prey (Barrett 1991, Velando \& Freire 1999, Lilliendahl \& Solmundsson 2006, Cosolo et al. 2011, Michelot et al. 2017) and can adjust their foraging behaviour in response to a change in availability of different prey types within their foraging range (Wanless et al. 1998, Daunt et al. 2007, Bogdanova et al. 2014, Michelot et al. 2017). Changes in the availability of sandeels, non-sandeels or both may have contributed to the diet shift in our study population since many fish species have experienced changes in abundance and distribution in the North Sea linked to ocean warming (Perry et al. 2005, Hiddink \& ter Hofstede 2008, Heath et al. 2012). However, this is challenging to investigate in detail in the absence of independent prey abundance data. The decline in estimated sandeel length may also have been a contributory factor underpinning the diet shift, since length is an index of energetic value (Hislop et al. 1991). This trend is in line with wider evidence of climate-mediated changes in the quality of sandeel in North Sea aggregations over the past 3 decades (Wanless et al. 2004, van Deurs et al. 2014). In particular, the decline of inshore sandeel aggregations fed on by shags mirrors those recorded in offshore aggregations targeted by Atlantic puffins Fratercula arctica breeding on the Isle of May (Wanless et al. 2004, Harris \& Wanless 2011). However, it is not possible to compare the extent of the change in fish length of inshore and offshore sandeels quantitatively because lengths in puffin diet are measured from intact fish, whereas those from shags are estimated from otolith length/fish length regression equations derived from sandeels in the diet of puffins. The parallel decline in sandeels and Callionymidae in the shag's diet may suggest a common environmental driver: the 2 likely species in the Callionymidae family, the common dragonet Callionymus lyra and the spotted dragonet C. maculatus, are associated with sandy habitats in common with sandeels (Heessen et al. 2015). In addition, Callionymidae may be encountered more frequently by chance when shags are searching for sandeels, and vice versa, leading to covariance in dietary proportions.

\section{Environmental covariates}

\section{Annual effects}

There was a negative relationship between the proportion of $1+$ group relative to 0 group sandeel

Table 5. Response variables and fixed effects included in the final models of sample-level biomass proportions and prey richness in relation to environmental covariates of European shag diet. Estimates $( \pm \mathrm{SE}), t$ - and $\mathrm{p}$-values are reported. $t-1$ indicates that covariates are lagged by 1 yr. No fixed effects were found to be significant for the Gadidae model. SST: sea surface temperature

\begin{tabular}{|c|c|c|c|c|c|}
\hline Response & Fixed effect & Estimate & $\mathrm{SE}$ & $t$ & $\mathrm{p}$ \\
\hline \multirow[t]{2}{*}{ Sandeel relative to all non-sandeel prey } & Mean daily wind speed $\left(\mathrm{m} \mathrm{s}^{-1}\right)$ & -0.06 & 0.03 & -2.23 & 0.026 \\
\hline & Breeding population size & $<0.01$ & $<0.01$ & 3.90 & $<0.001$ \\
\hline \multirow[t]{2}{*}{$1+$ relative to 0 group sandeel } & SST $t-1$ & -2.06 & 0.69 & -2.98 & 0.006 \\
\hline & Day-of-year & -0.09 & 0.01 & -7.38 & $<0.001$ \\
\hline \multirow[t]{2}{*}{ Pholidae relative to other non-sandeel prey } & $\mathrm{SST} t-1$ & 1.73 & 0.44 & 3.95 & $<0.001$ \\
\hline & Calanus finmarchicus abundance & -0.24 & 0.09 & 3.95 & 0.011 \\
\hline \multirow{3}{*}{$\begin{array}{l}\text { Callionymidae relative to other non-sandeel } \\
\text { prey }\end{array}$} & Calanus nauplii abundance & 0.05 & 0.02 & 3.31 & 0.003 \\
\hline & Calanus nauplii abundance $t-1$ & 0.05 & 0.02 & 3.14 & 0.005 \\
\hline & Breeding population size & $<0.01$ & $<0.01$ & 2.98 & 0.007 \\
\hline \multirow[t]{3}{*}{ Sample-level prey richness } & $\mathrm{SST} t-1$ & 0.97 & 0.34 & 2.85 & 0.009 \\
\hline & Calanus nauplii abundance & -0.03 & 0.01 & -2.20 & 0.037 \\
\hline & Breeding population size & $-<0.01$ & $<0.01$ & -3.09 & 0.005 \\
\hline
\end{tabular}


and SST in the previous year. Sandeel recruitment is strongly dependent on temperature, mediated by changes to key zooplankton prey species, in particular Calanus finmarchicus (Arnott \& Ruxton 2002, van Deurs et al. 2009). Thus, this relationship suggests that temperatures in the previous year affect the abundance, size or quality of the $1+$ group in the current year (van Deurs et al. 2009) and, in turn, shag diet. The proportion of Pholidae relative to other non-sandeel prey was greater following warmer SST in the previous year. The Pholidae prey class contained solely the rock butterfish or gunnel Pholis gunnellus (hereafter butterfish), which are primarily associated with rocky and other coarse habitats (Shorty \& Gannon 2013). In Iceland, butterfish are larger in warmer water (Gunnarsson \& Gunnarsson 2002), and, in fish in general, the timing of egg hatching is inversely related to temperature, which hastens development (Pauly \& Pullin 1988). Earlier hatching in warmer years may thus extend the period of larval growth, increasing butterfish size and therefore profitability of this prey type for shags in the following year (Gunnarsson \& Gunnarsson 2002). Such physiological processes will not be
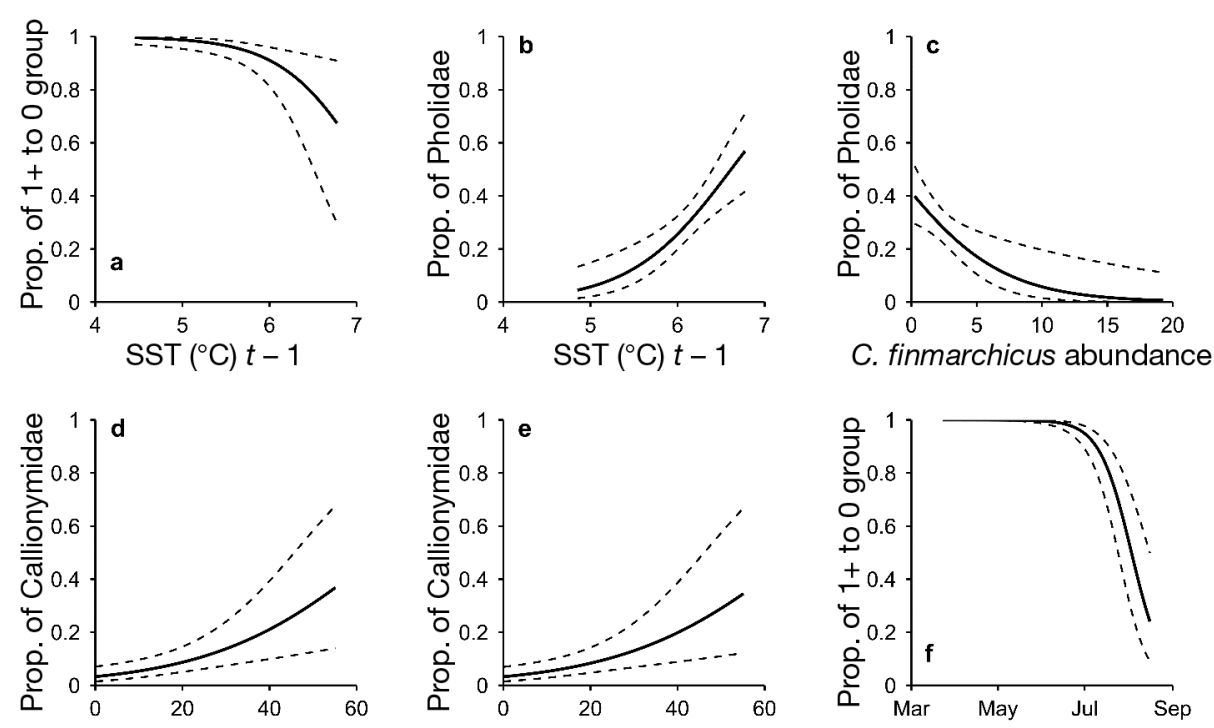

Calanus nauplii abundance
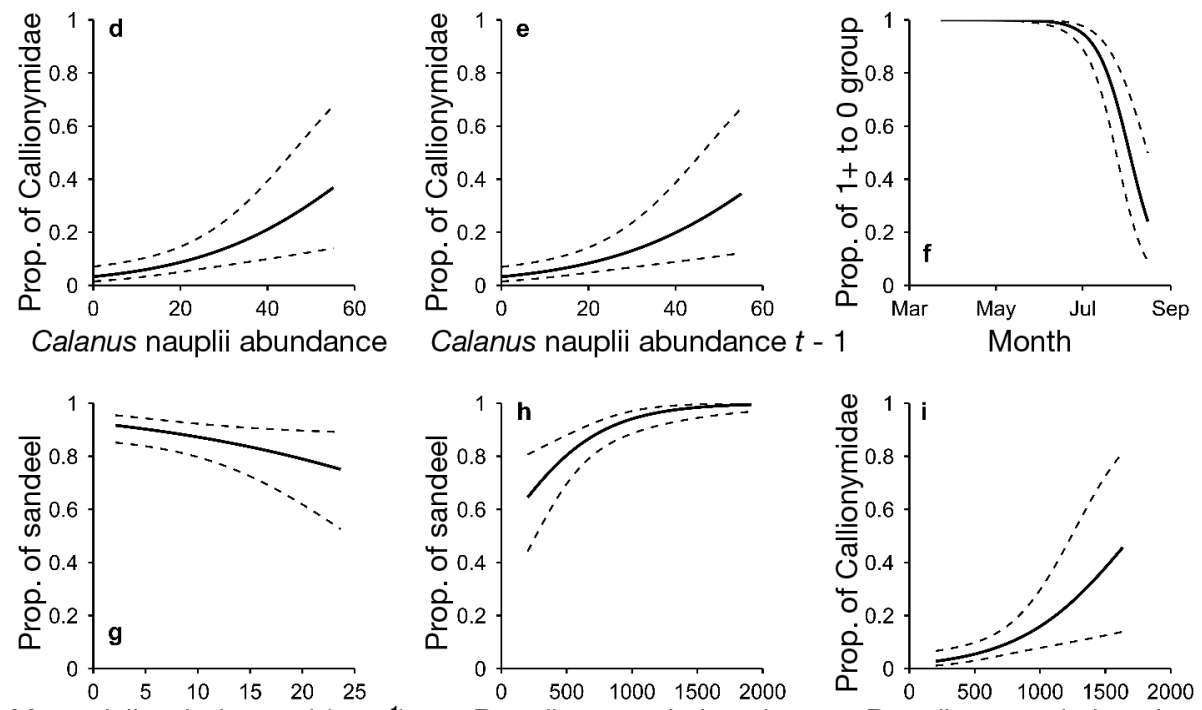

Calanus nauplii abundance $t-1$
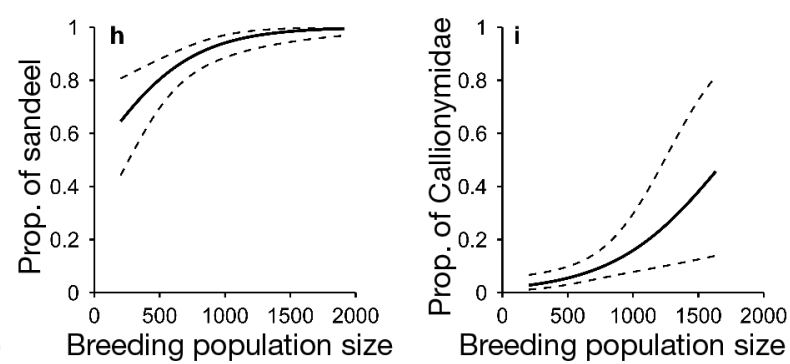

Fig. 4. Fitted lines $( \pm 95 \% \mathrm{CI})$ for proportion of each of the modelled prey types occurring in the diet of European shag in relation to significant fixed effects in the final models. (a) Proportion of $1+$ relative to 0 group sandeel prey in relation to sea surface temperature $\left({ }^{\circ} \mathrm{C}\right.$ ) in the previous year; (b) proportion of Pholidae relative to nonsandeel prey in relation to sea surface temperature $\left({ }^{\circ} \mathrm{C}\right)$ in the previous year and (c) in relation to mean spring Calanus finmarchicus abundance $\mathrm{mo}^{-1}$ in the current year; (d) proportion of Callionymidae relative to non-sandeel prey in relation to mean spring Calanus nauplii abundance $\mathrm{mo}^{-1}$ in the current year and (e) in relation to mean spring Calanus nauplii abundance $\mathrm{mo}^{-1}$ in the preceding year; (f) proportion of $1+$ relative to 0 group sandeel prey in relation to day of year (presented as month to aid interpretation); ( $\mathrm{g}$ ) proportion of sandeel relative to all prey in relation to mean daily wind speed $\left(\mathrm{m} \mathrm{s}^{-1}\right)$ and $(\mathrm{h})$ in relation to breeding population size; and (i) proportion of Callionymidae (relative to all non-sandeel prey) relative to breeding population size. Values are only displayed over the range for which data were included in the model. Predictions were made using binomial generalised linear mixed models (GLMMs) and setting additional fixed effects at the mean value. $t-1$ indicates that effects are lagged by 1 yr
Fig. 5. Fitted lines $( \pm 95 \% \mathrm{CI})$ for samplelevel prey richness in relation to significant fixed effects in the final model of European shag diet: (a) sea surface temperature $\left({ }^{\circ} \mathrm{C}\right)$ in the previous year, (b) mean spring Calanus nauplii abundance $\mathrm{mo}^{-1}$ in the current year, and (c) breeding population size. Values are only displayed over the range for which data were included in the model. Predictions were made using Poisson generalised linear mixed models (GLMMs) and by setting additional fixed effects at the mean value. $t-1$ indicates that effects are lagged by $1 \mathrm{yr}$
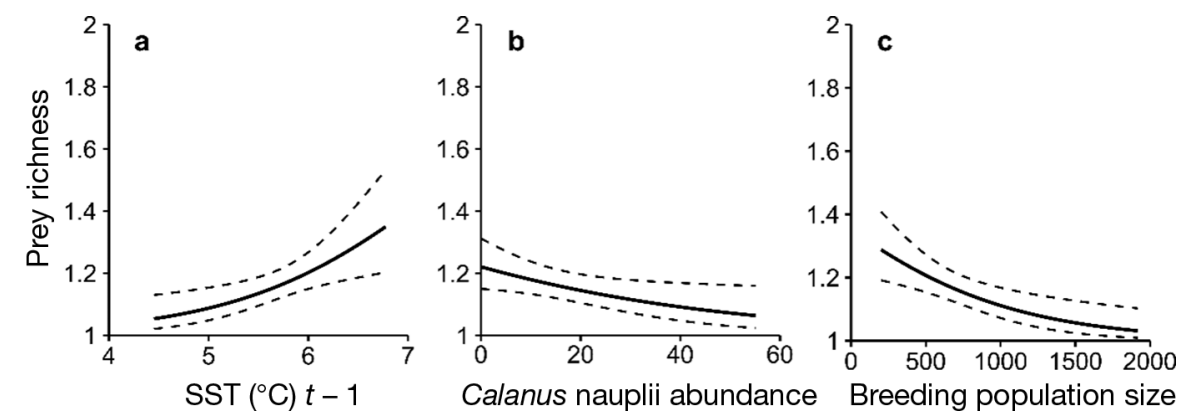
unique to butterfish, but our patterns indicate that these may be overridden in other prey by factors such as food limitation. Our results suggest that the opposite effects of temperature on the proportions of 1+ group sandeel and Pholidae were independent, rather than a change in the abundance or availability of one type leading to a reciprocal dietary increase in the other. The positive effect of lagged SST on prey richness suggests that the abundance of 1+ group sandeel is reduced by higher temperatures in the preceding year, leading to diet diversification. Similar responses have been observed in other seabirds (Gaston \& Elliott 2014), which further supports the theory that in species with plastic foraging strategies, diet diversifies when the dominant prey becomes scarce or unprofitable in particular environmental conditions (Stephens \& Krebs 1986). Despite the increasing trend over time in SST, there was no trend in the relative proportions of different sandeel age classes or the proportion of Pholidae relative to other non-sandeel prey, 2 of the diet variables affected by SST. However, there was an increasing trend in the third variable associated with SST, prey richness, which suggests that temperature was an important driver of diet diversification in this population, and accords with evidence for an increase in fish diversity in the North Sea (Hiddink \& ter Hofstede 2008).

Unexpectedly, no effect of either of the Calanus abundance measures was found on the proportion of sandeels in the diet. Perhaps inshore sandeel populations exploited by shags may have different scheduling of life history events or environmental determinants from other North Sea populations, upon which our choice of covariates was based (Arnott \& Ruxton 2002, van Deurs et al. 2009). Alternatively, these measures may not be reliable as annual proxies of sandeel abundance. We selected $C$. finmarchicus abundance as a proxy of egg production, since eggs and nauplii of this species are key prey of younger age classes of sandeel (van Deurs et al. 2009). Thus, there are multiple intermediate steps connecting $C$. finmarchicus and sandeel abundance that may each serve to weaken the relationship between them. Our second measure (Calanus nauplii) may also not be a reliable index of sandeel abundance since it comprises all Calanus species combined, including species with a preference for warmer sea temperatures that may not be important in the diet of sandeels (Beaugrand 2004). The negative relationship between the proportion of Pholidae relative to nonsandeel prey and C. finmarchicus abundance suggests that other non-sandeel prey may increase in abundance, size or profitability in years of high $C$. finmarchicus abundance. The positive effect of Calanus nauplii abundance in the current and preceding year on the proportion of Callionymidae is in line with this. Callionymidae are opportunistic feeders so may utilise abundant Calanus nauplii when they are available (Griffin et al. 2012). This link may also underpin the negative relationship between prey richness and Calanus nauplii, whereby good feeding conditions for Callionymidae may result in shags reducing the consumption of other non-sandeel prey, leading to lower diet diversity. However, the concurrent increase in Calanus nauplii abundance and decrease in the proportion of Callionymidae suggests that the trend in Callionymidae is likely to have been caused by some other factor.

\section{Seasonal effects}

We demonstrated a seasonal switch from 1+ group to 0 group sandeels in shag diet. Such a pattern is likely to be related to the temporal availability of the different sandeel age classes, with the 0 group becoming available in the water column in June as the $1+$ group returns to the seabed following their active spring feeding phase (Wright \& Bailey 1993). This switch has previously been shown in other seabird species breeding in the region (Lewis et al. 2001a, Wanless et al. 2004, Daunt et al. 2008). However, in contrast to these species, which shift to 0 group when they become available in June, shags switched to the 0 group a month later. Shags can extract sandeel directly from the seabed, so 1+ sandeels remain potentially available throughout the breeding season (Watanuki et al. 2008). Thus, they may switch to 0 group sandeels when these have grown large enough or if their large pelagic shoals move close enough to the island to be more profitable than the buried 1+ group (Wanless et al. 1998). Alternatively, the timing of metamorphosis of inshore 0 group sandeels may be later in inshore populations than those offshore, although currently we have no data to test this assertion. Although the date of sample collection became earlier over the study period, related to advances in population phenology $\left(\mathrm{r}_{\mathrm{S}}=0.66\right)$, this trend did not appear to drive the relative proportions of different sandeel age classes, which showed no trend over time. This advance in timing of breeding is also unlikely to have explained the decline in sandeels in the diet relative to non-sandeels, since there was no seasonal pattern in relative proportions of these 2 prey types. 


\section{Daily effects}

The lower proportion of sandeel in the diet at higher wind speeds supports other studies which have demonstrated that weather conditions alter diet composition in seabirds (Finney et al. 1999, Stienen et al. 2000, Elliott et al. 2014). This relationship may be linked to wind effects on foraging or flight ability (Daunt et al. 2006, 2014, Lewis et al. 2015, Kogure et al. 2016). Enhanced water turbidity during strong winds may alter sandeel availability or catchability (Dunn 1973), while increased flight costs in windier conditions, as is evident in species with flapping flight (Gabrielsen et al. 1991), may lead to individuals selecting different habitats and associated prey. Alternatively, high wind speeds may increase the availability of non-sandeel prey, although the mechanisms are unknown. However, despite detecting a significant negative effect of daily wind speed on the proportion of sandeel in the diet, there was no evidence that average daily wind speeds during the breeding season changed over the course of the study, and therefore we do not think that weather conditions contributed to the long-term decline in importance of sandeels.

\section{Population density}

Theory and empirical evidence suggests that population density during the breeding season has the potential to affect diet composition of seabirds since adults may experience high intraspecific competition leading to prey depletion, which may not be equal across prey types (Ashmole 1963, Birt et al. 1987, Lewis et al. 2001b). Shags and other inshore species may be particularly susceptible to this effect because of their highly restricted foraging range in the breeding season (mean $\pm \mathrm{SD}$ max. range bird ${ }^{-1}$ in the Isle of May breeding population: $17.7 \pm 8.4 \mathrm{~km}$; Bogdanova et al. 2014). However, breeding population size, which declined markedly over the study period, was removed from all models in the detrending analysis, suggesting that other factors were more important in explaining the dietary trends.

\section{Consequences of dietary change}

Understanding the environmental drivers of diet composition over a range of temporal scales can provide important insights into the environmental causes of current and future change in seabird populations, since diet composition is a key determinant of seabird demography (Monaghan et al. 1989, Reid \& Croxall 2001). Key metrics underpinning this link are prey capture rate (which integrates search and handling times) and energetic value. Variation in foraging efficiency associated with these measures may affect chick growth rates and adult body condition and, in turn, breeding success, post-fledging survival or adult survival (Olsson 1997, Davis et al. 2005). Energy density appears similar between sandeels and the majority of alternative prey for which data exist (Spitz et al. 2010). However, in order to investigate the potential consequences of the diet shift, locally estimated energetic value (integrating prey size and energy density) and capture rates of different prey is a priority for future work. The diversification in diet means that shags now forage for prey associated with a broader range of habitats than they did at the start of the study period, including those associated with rocky habitats (Watanuki et al. 2008). Such changes may alter interactions with potential threats, such as small-scale offshore renewable developments. In 2000, the UK had $34 \%$ of the global population of European shags (Wanless \& Harris 2004), but by 2015 the UK population had declined by $34 \%$ (JNCC 2016). This is in line with similar declines observed in other sandeel-dependent species, such as the black-legged kittiwake Rissa tridactyla, which declined by $44 \%$ over the same period (JNCC 2016). Given predictions of an increase in climatic mean and variability in many regions (IPCC 2014), there may be further changes in shag diet. In particular, the link between SST and prey richness that we observed suggests that ocean warming may lead to further diet generalisation, while an increased frequency and severity of extreme wind events may further reduce the dietary contribution of sandeel. Such changes could have important consequences for future population dynamics in this species.

Acknowledgements. We thank the many people who helped with fieldwork over the last 3 decades, in particular Jenny Bull, Linda Wilson and Carrie Gunn; we also thank Sam Tomlinson, Adam Vanbergen and Dan Chapman for help with manipulation and analysis of the data. We thank 3 anonymous referees and the contributing editor, Kyle Elliott, for constructive criticism and useful suggestions on improving the manuscript. We thank the Natural Environment Research Council (NERC) Adapting to the Challenges of a Changing Environment Doctoral Training Partnership (ACCE DTP), NERC National Capability, NERC/Department for Environment, Food and Rural Affairs (DEFRA) Marine Ecosystems Research Programme (grant number NE/L003082/1) and Joint Nature Conservation Committee (JNCC) for funding, and the Scottish Natural Heritage for access to the Isle of May National Nature Reserve. The work was conducted under research licences from the Scottish Natural Heritage. 


\section{LITERATURE CITED}

Arnott SA, Ruxton GD (2002) Sandeel recruitment in the North Sea: demographic, climatic and trophic effects. Mar Ecol Prog Ser 238:199-210

Ashmole NP (1963) The regulation of numbers of tropical oceanic birds. Ibis 103b:458-473

*Barrett RT (1991) Shags (Phalacrocorax aristotelis L.) as potential samplers of juvenile saithe (Pollachius virens (L.)) stocks in northern Norway. Sarsia 76:153-156

Barrett RT, Camphuysen K, Anker-Nilssen T, Chardine JW and others (2007) Diet studies of seabirds: a review and recommendations. ICES J Mar Sci 64:1675-1691

Bartoń K (2016) Multi-model inference 'MuMIn'. R package version 1.40.0. https://CRAN.R-project.org/package= MuMIn

Bates D, Maechler M, Bolker B, Walker S (2014) lme4: linear mixed-effects models using Eigen and S4. R package version 1.1-6. http://lme4.r-forge.r-project.org

Beaugrand G (2004) The North Sea regime shift: evidence, causes, mechanisms and consequences. Prog Oceanogr 60:245-262

Birt VL, Birt TP, Goulet D, Cairns DK, Montevecchi WA (1987) Ashmole's halo: direct evidence for prey depletion by a seabird. Mar Ecol Prog Ser 40:205-208

Bogdanova MI, Wanless S, Harris MP, Lindström J and others (2014) Among-year and within-population variation in foraging distribution of European shags Phalacrocorax aristotelis over two decades: implications for marine spatial planning. Biol Conserv 170:292-299

Boyce MS, Haridas CV, Lee CT (2006) Demography in an increasingly variable world. Trends Ecol Evol 21:141-148

Burnham KP, Anderson DR (2002) Model selection and multimodel inference: a practical information-theoretic approach, 2nd edn. Springer-Verlag, New York, NY

Burthe S, Daunt F, Butler A, Elston DA and others (2012) Phenological trends and trophic mismatch across multiple levels of a North Sea pelagic food web. Mar Ecol Prog Ser 454:119-133

Campbell RD, Nouvellet P, Newman C, MacDonald DW, Rosell F (2012) The influence of mean climate trends and climate variance on beaver survival and recruitment dynamics. Glob Change Biol 18:2730-2742

Cosolo M, Privileggi N, Cimador B, Sponza S (2011) Dietary changes of Mediterranean shags Phalacrocorax aristotelis desmarestii between the breeding and post-breeding seasons in the upper Adriatic Sea. Bird Study 58:461-472

Croxall JP, Reid K, Prince PA (1999) Diet, provisioning and productivity responses of marine predators to differences in availability of Antarctic krill. Mar Ecol Prog Ser 177: 115-131

* Cury P, Bakun A, Crawford RJM, Jarre A, Quiñones RA, Shannon L, Verheye HM (2000) Small pelagics in upwelling systems: patterns of interaction and structural changes in 'wasp-waist' ecosystems. ICES J Mar Sci 57: $603-618$

Daunt F, Mitchell I (2013) Impacts of climate change on seabirds. MCCIP Sci Rev 2013:125-133

Waunt F, Afanasyev V, Silk JRD, Wanless S (2006) Extrinsic and intrinsic determinants of winter foraging and breeding phenology in a temperate seabird. Behav Ecol Sociobiol 59:381-388

Daunt F, Wanless S, Harris MP, Money L, Monaghan P (2007) Older and wiser: improvements in breeding success are linked to better foraging performance in Euro- pean shags. Funct Ecol 21:561-567

* Daunt F, Wanless S, Greenstreet SPR, Jensen H, Hamer KC, Harris MP (2008) The impact of the sandeel fishery closure in the northwestern North Sea on seabird food consumption, distribution and productivity. Can J Fish Aquat Sci 65:362-381

* Daunt F, Reed TE, Newell M, Burthe S, Phillips RA, Lewis S, Wanless S (2014) Longitudinal bio-logging reveals interplay between extrinsic and intrinsic carry-over effects in a long-lived vertebrate. Ecology 95:2077-2083

* Davis SE, Nager RG, Furness RW (2005) Food availability affects adult survival as well as breeding success of parasitic jaegers. Ecology 86:1047-1056

* Davoren GK, Montevecchi WA (2003) Signals from seabirds indicate changing biology of capelin stocks. Mar Ecol Prog Ser 258:253-261

Drent R, Daan S (1980) The prudent parent: energetic adjustments in avian breeding. Ardea 68:225-252

Dunn EK (1973) Changes in fishing ability of terns associated with windspeed and sea surface conditions. Nature 244:520-521

米Durant JM, Hjermann D, Anker-Nilssen T, Beaugrand G, Mysterud A, Pettorelli N, Stenseth NC (2005) Timing and abundance as key mechanisms affecting trophic interactions in variable environments. Ecol Lett 8:952-958

* Durant JM, Hjermann DØ, Ottersen G, Stenseth NC (2007) Climate and the match or mismatch between predator requirements and resource availability. Clim Res 33: 271-283

* Edwards M, Richardson AJ (2004) Impact of climate change on marine pelagic phenology and trophic mismatch. Nature 430:881-884

FElliott KH, Chivers LS, Bessey L, Gaston AJ and others (2014) Windscapes shape seabird instantaneous energy costs but adult behavior buffers impact on offspring. Mov Ecol 2:17

Finney SK, Wanless S, Harris MP (1999) The effect of weather conditions on the feeding behaviour of a diving bird, the common guillemot Uria aalge. J Avian Biol 30:23-30

Frederiksen M, Harris MP, Daunt F, Rothery P, Wanless S (2004) Scale-dependent climate signals drive breeding phenology of three seabird species. Glob Change Biol 10:1214-1221

Frederiksen M, Edwards M, Richardson AJ, Halliday NC, Wanless S (2006) From plankton to top predators: bottom-up control of a marine food web across four trophic levels. J Anim Ecol 75:1259-1268

FFrederiksen M, Elston DA, Edwards M, Mann AD, Wanless S (2011) Mechanisms of long-term decline in size of lesser sandeels in the North Sea explored using a growth and phenology model. Mar Ecol Prog Ser 432:137-147

Fretwell SD (1972) Populations in a seasonal environment. Princeton University Press, Princeton, NJ

Furness R (1982) Population, breeding biology and diets of seabirds on Foula in 1980. Seabird 6:13-17

F Furness RW, Tasker ML (2000) Seabird-fishery interactions: quantifying the sensitivity of seabirds to reductions in sandeel abundance, and identification of key areas for sensitive seabirds in the North Sea. Mar Ecol Prog Ser 202:253-264

Gabrielsen GW, Taylor JRE, Konarzewski M, Mehlum F (1991) Field and laboratory metabolism and thermoregulation in dovekies (Alle alle). Auk 108:71-78

Gaston AJ, Elliott KH (2014) Seabird diet changes in northern Hudson Bay, 1981-2013, reflect the availability of 
schooling prey. Mar Ecol Prog Ser 513:211-223

Green DB, Klages NTW, Crawford RJM, Coetzee JC, Dyer BM, Rishworth GM, Pistorius PA (2015) Dietary change in Cape gannets reflects distributional and demographic shifts in two South African commercial fish stocks. ICES J Mar Sci 72:771-781

*Gémillet D, Lewis S, Drapeau L, van der Lingen CD and others (2008) Spatial match-mismatch in the Benguela upwelling zone: Should we expect chlorophyll and seasurface temperature to predict marine predator distributions? J Appl Ecol 45:610-621

* Griffin R, Pearce B, Handy RD (2012) Dietary preference and feeding selectivity of common dragonet Callionymus lyra in UK. J Fish Biol 81:1019-1031

Grosbois V, Gimenez O, Gaillard JM, Pradel R and others (2008) Assessing the impact of climate variation on survival in vertebrate populations. Biol Rev Camb Philos Soc 83:357-399

Gunnarsson A, Gunnarsson K (2002) Temperature effects on growth and maturity of butterfish (Pholis gunnellus) in Iceland. J Mar Biol Assoc UK 82:903-906

Härkönen T (1986) Guide to the otoliths of the bony fishes of the northeast Atlantic. Danbiu ApS, Hellerup

Harris MP, Wanless S (1991) The importance of the lesser sandeel Ammodytes marinus in the diet of the shag Phalacrocorax aristotelis. Ornis Scand 22:375-382

* Harris MP, Wanless S (1993) The diet of shags Phalacrocorax aristotelis during the chick-rearing period assessed by three methods. Bird Study 40:135-139

Harris MP, Wanless S (2011) The puffin, 1st edn. T \& AD Poyser, London

*Hays GC, Richardson AJ, Robinson C (2005) Climate change and marine plankton. Trends Ecol Evol 20:337-344

Heath MR, Neat FC, Pinnegar JK, Reid DG, Sims DW, Wright PJ (2012) Review of climate change impacts on marine fish and shellfish around the UK and Ireland. Aquat Conserv 22:337-367

Heessen HJL, Daan N, Ellis JR (2015) Fish atlas of the Celtic Sea, North Sea, and Baltic Sea, 1st edn. KNNV Publishing; Wageningen Academic Publishers

Hiddink JG, ter Hofstede R (2008) Climate induced increases in species richness of marine fishes. Glob Change Biol $14: 453-460$

Hillersøy G, Lorentsen SH (2012) Annual variation in the diet of breeding European shag (Phalacrocorax aristotelis) in central Norway. Waterbirds 35:420-429

Hislop JRG, Harris MP, Smith JGM (1991) Variation in the calorific value and total energy content of the lesser sandeel (Ammodytes marinus) and other fish preyed on by seabirds. J Zool (Lond) 224:501-517

Høyer JL, Karagali I (2016) Sea surface temperature climate data record for the North Sea and Baltic Sea. J Clim 29: 2529-2541

ICES (1995) Report of the ICES workshop on sandeel otolith analysis: review of sandeel biology. ICES CM 1995/G:4. ICES, Copenhagen

IPCC (2014) Climate change 2014: synthesis report. Contribution of Working Groups I, II and III to the Fifth Assessment Report of the Intergovernmental Panel on Climate Change. IPCC, Geneva

JNCC (Joint Nature Conservation Committee) (2016) Seabird population trends and causes of change: 1986-2015 report. Joint Nature Conservation Committee, Peterborough

Kogure Y, Sato K, Watanuki Y, Wanless S, Daunt F (2016) European shags optimize their flight behavior according to wind conditions. J Exp Biol 219:311-318

* Lewis S, Wanless S, Wright PJ, Harris MP, Bull J, Elston DA (2001a) Diet and breeding performance of black-legged kittiwakes Rissa tridactyla at a North Sea colony. Mar Ecol Prog Ser 221:277-284

Kewis S, Sherratt TN, Hamer KC, Wanless S (2001b) Evidence of intra-specific competition for food in a pelagic seabird. Nature 412:816-819

Lewis S, Sherratt TN, Hamer KC, Harris MP, Wanless S (2003) Contrasting diet quality of northern gannets Morus bassanus at two colonies. Ardea 9:167-176

K Lewis S, Phillips RA, Burthe SJ, Wanless S, Daunt F (2015) Contrasting responses of male and female foraging effort to year-round wind conditions. J Anim Ecol 84: 1490-1496

* Lilliendahl K, Solmundsson J (2006) Feeding ecology of sympatric European shags Phalacrocorax aristotelis and great cormorants P. carbo in Iceland. Mar Biol 149: 979-990

Macer CT (1966) Sand eels (Ammodytidae) in the southwestern North Sea: their biology and fishery. Fishery Investigations, Series 2, Vol 24. HM Stationery Office, London

Michelot C, Pinaud D, Fortin M, Maes P, Callard B, Leicher M, Barbraud C (2017) Seasonal variation in coastal marine habitat use by the European shag: insights from fine scale habitat selection modeling and diet. Deep Sea Res II 141:224-236

Miller AK, Sydeman WJ (2004) Rockfish response to lowfrequency ocean climate change as revealed by the diet of a marine bird over multiple time scales. Mar Ecol Prog Ser 281:207-216

Mitchell PI, Newton SF, Ratcliffe NR, Dunn TE (2004) Seabird populations of Britain and Ireland. T \& AD Poyser, London

Monaghan P, Uttley JD, Burns MD, Thaine C, Blackwood J (1989) The relationship between food supply, reproductive effort and breeding success in Arctic terns Sterna paradisaea. J Anim Ecol 58:261-274

Olsson O (1997) Effects of food availability on fledging condition and post-fledging survival in king penguin chicks. Polar Biol 18:161-165

Orians GH, Pearson NE (1979) On the theory of central place foraging. In: Horn JD, Mitchel RD, Stairs GR (eds) Analysis of ecological systems. Ohio State University Press, Columbus, OH, p 155-177

* Pauly D, Pullin RSV (1988) Hatching time in spherical, pelagic, marine fish eggs in response to temperature and egg size. Environ Biol Fishes 22:261-271

*Perry AL, Low PJ, Ellis JR, Reynolds JD (2005) Climate change and distribution shifts in marine fishes. Science 308:1912-1915

* Poloczanska ES, Brown CJ, Sydeman WJ, Kiessling W and others (2013) Global imprint of climate change on marine life. Nat Clim Chang 3:919-925

R Development Core Team (2016) R: a language and environment for statistical computing. R Foundation for Statistical Computing, Vienna

Reid K, Croxall JP (2001) Environmental response of upper trophic-level predators reveals a system change in an Antarctic marine ecosystem. Proc R Soc B 268:377-384

Reid PC, Colebrook JM, Matthews JBL, Aiken J and others (2003) The continuous plankton recorder: concepts and history, from plankton indicator to undulating recorders. Prog Oceanogr 58:117-173 
Rindorf A, Wright PJ, Jensen H, Maar M (2016) Spatial differences in growth of lesser sandeel in the North Sea. J Exp Mar Biol Ecol 479:9-19

Sagar P, Sagar JL (1989) The effects of wind and sea on the feeding of Antarctic terns at the Snares Islands, New Zealand. Notornis 36:171-182

Shorty JT, Gannon DP (2013) Habitat selection by the rock gunnel, Pholis gunnellus L. (Pholidae). Northeast Nat (Steuben) 20:155-171

Spitz J, Mourocq E, Schoen V, Ridoux V (2010) Proximate composition and energy content of forage species from the Bay of Biscay: High- or low-quality food? ICES J Mar Sci 67:909-915

Stephens DW, Krebs JR (1986) Foraging theory. Princeton University Press, Princeton, NJ

Steven G (1933) The food consumed by shags and cormorants around the shores of Cornwall (England). J Mar Biol Assoc UK 19:277-292

Stienen EWM, van Beers PWM, Brenninkmeijer A, Habraken JMPM, Raaijmakers MHJE, van Tienen PGM (2000) Reflections of a specialist: patterns in food provisioning and foraging conditions in Sandwich tern Sterna sandvicensis. Ardea 88:33-49

Sydeman WJ, Poloczanska ES, Reed TE, Thompson SA (2015) Climate change and marine vertebrates. Science 350:772-777

*van Deurs M, van Hal R, Tomczak MT, Jónasdóttir SH, Dolmer P (2009) Recruitment of lesser sandeel Ammodytes marinus in relation to density dependence and zooplankton composition. Mar Ecol Prog Ser 381: 249-258

van Deurs M, Koski M, Rindorf A (2014) Does copepod size determine food consumption of particulate feeding fish? ICES J Mar Sci 71:35-43

Velando A, Freire J (1999) Intercolony and seasonal differences in the breeding diet of European shags on the Galician coast (NW Spain). Mar Ecol Prog Ser 188: 225-236

Venables WN, Ripley BD (2002) Modern applied statistics with S, 4th edn. Springer, New York, NY

Walsh PM, Halley DJ, Harris MP, Nevo A del, Sim IMW, Tasker ML (1995) Seabird monitoring handbook for

Editorial responsibility: Kyle Elliott,

Sainte-Anne-de-Bellevue, Québec, Canada
Britain and Ireland. JNCC/RSPB/ITE/Seabird Group, Peterborough

Wanless S, Harris M (2004) European shag Phalacrocorax aristotelis. In: Mitchell P, Newton S, Ratcliffe N, Dunn T (eds) Seabird populations in Britain and Ireland. T \& AD Poyser, London, p 146-159

*Wanless S, Harris MP, Russel AF (1993) Factors influencing food-load sizes brought in by shags Phalacrocorax aristotelis during chick rearing. Ibis 135:19-24

*Wanless S, Gremillet D, Harris MP (1998) Foraging activity and performance of shags in relation to environmental characteristics. J Avian Biol 29:49-54

*Wanless S, Wright PJ, Harris MP, Elston DA (2004) Evidence for decrease in size of lesser sandeels Ammodytes marinus in a North Sea aggregation over a 30-yr period. Mar Ecol Prog Ser 279:237-246

*Watanuki Y, Daunt F, Takahashi A, Newell M, Wanless S, Sato K, Miyazaki N (2008) Microhabitat use and prey capture of a bottom-feeding top predator, the European shag, shown by camera loggers. Mar Ecol Prog Ser 356:283-293

Watt J, Pierce GJ, Boyle PR (1997) Guide to the identification of North Sea fish using premaxillae and vertebrae. ICES Coop Res Rep 220. ICES, Copenhagen

Weimerskirch H, Guionnet T, Martin J, Shaffer SA, Costa DP (2000) Fast and fuel efficient? Optimal use of wind by flying albatrosses. Proc R Soc B 267:1869-1874

White TCR (2008) The role of food, weather and climate in limiting the abundance of animals. Biol Rev Camb Philos Soc 83:227-248

Wickham H (2009) ggplot2: elegant graphics for data analysis. Springer-Verlag, New York, NY

*Winslade P (1974) Behavioural studies on the lesser sandeel Ammodytes marinus (Raitt) III. The effect of temperature on activity and the environmental control of the annual cycle of activity. J Fish Biol 6:587-599

Wright P, Bailey M (1993) Biology of sandeels in the vicinity of seabird colonies at Shetland. Scottish Fisheries Research Report No. 15/93. Department of Agriculture and Fisheries, Aberdeen

W Wright PJ, Bailey MC (1996) Timing of hatching in Ammodytes marinus from Shetland waters and its significance to early growth and survivorship. Mar Biol 126:143-152

Submitted: June 12, 2017; Accepted: September 18, 2017 Proofs received from author(s): October 30, 2017 